\title{
CONSTITUCIÓN ESPAÑOLA DE CÁDIZ 1812
}

ALEJANDRO CARRIÓN PÉREZ

Universidad Central del Ecuador 
Se nos ha convocado para mirar la trascendencia de la Constitución de Cádiz en España y América. Para ver su presencia en el desarrollo del Derecho Constitucional y en las instituciones políticas de los Estados contemporáneos. Por tan importante iniciativa felicitamos a los promotores de este evento, particularmente a la Embajada de España, a las universidades e instituciones que lo han hecho posible.

En opinión del Rector de Universidad de Cádiz, "la ciudad portuaria de Cádiz desplegó las velas de la libertad y exportó democracia por todo el continente americano. Nunca una ciudad sitiada llegó tan lejos en sus proclamas y en sus ambiciones". Por ello nuestro saludo a Cádiz y a su espíritu revolucionario que nos ha dejado este legado positivo.

Nuestro reconocimiento histórico, a La Constitución de Cádiz, proclamada el 8 de junio de 1812 con la presencia de diputados hispanoamericanos por su influencia en los movimientos de emancipación de América Latina con mención especial de honor a José Mejía Lequerica y a José Joaquín Olmedo.

Nuestra satisfacción profunda por cuanto, el espíritu constitucional de Cádiz, nos lleva a reafirmar nuestra fe en la democracia y nuestra vocación de constitucionalistas, para fortalecer la institucionalidad de nuestros países lamentablemente azotados en estos doscientos años, por sus problemas estructurales y coyunturales y por la alternabilidad de democracia, dictadura y fraude electoral.

Saludamos a la Constitución de Cádiz por promover la tesis de la soberanía nacional y la división de poderes; buscar la igualdad de los ciudadanos ante la ley; promover el reconocimiento de derechos individuales $y$ abolir la tortura.

Apreciamos la validez de la Constitución de Cádiz para los tiempos que vivimos en su planteamiento contra los absolutismos y su establecimiento de controles al poder político.

Reconocemos que si bien la Constitución de Cádiz tuvo una vida breve y azarosa, signada por las condiciones de su aprobación y del hostil contexto, marcó el camino que en España condujo a una monarquía constitucional parlamentaria y en América hispana a las repúblicas democráticas y presidenciales.

El contexto de 1808-1814 -signado por la resistencia a la ocupación napoleónica o "Independencia"- abrió la oportunidad para el desarrollo de un pensamiento a la vez nacionalista y democrático, que recogió lo mejor de las tradiciones políticas hispánicas -europeas y americanasenriquecidas por las ideas liberales de la época, de origen inglés, francés y norteamericano. Para los iberoamericanos, fue un evento que ratificó y dinamizó los procesos democráticos que ya se venían dando y que estuvieron luego vigentes en las constituciones de los nacientes Estados.

Más allá de haber establecido una religión oficial, conservar un excesivo poder a favor de la monarquía, mantener la esclavitud y de ser un extenso texto con diez títulos y 384 artículos, la Constitución de Cádiz da una sólida contribución al constitucionalismo del futuro, proyectando un Estado democrático con sus ideas liberales, aportando pensamientos nuevos a la sociedad y creando nuevas leyes que 
otorgaban más libertad a España y a sus colonias en América. Acelerando las independencias americanas y sentando los fundamentos ideológicos y jurídicos en los que se fundaron las repúblicas americanas.

Es menester señalar, que las importantes reformas de esta primera Constitución alcanzaron al ámbito político, económico y social. Destacándose la supresión de la Inquisición, la abolición de los regímenes señoriales y de los gremios, importantes desamortizaciones y una de las reformas más trascendentales: la libertad de imprenta que siempre debe ser libertad de pensamiento y de opinión.

Añadiendo, que todos estos decretos estaban guiados por los principios de libertad, igualdad ante la ley y propiedad privada.

De Cádiz emergen ciudadanos con derechos y representación política ciudadana. Hay racionalización del poder y responsabilidad pública.

En definitiva, la Constitución de Cádiz fue el nervio liberal del cual partieron los movimientos constitucionales en Hispanoamérica, fue también origen de nuevas instituciones, así como iniciación de políticas sociales y económicas. Jugó un papel decisivo en la consolidación de la independencia, que tuvo en el año 1815 una significativa crisis, como bien puede advertirse en la "Carta de Jamaica" firmada por Simón Bolívar, en la que solicita una integración multiterritorial: "Seguramente la unión es lo que nos falta para completar la obra de regeneración"; quizá el monarquismo de Bolívar quedó anclado en la desvirtuación de la monarquía por la misma Constitución de Cádiz.
En un estudio comparado entre la Constitución de Cádiz, la Constitución Francesa de 1791 y la Constitución estadounidense de 1787 diremos que las tres consagran semejantes derechos y libertades, establecen límites al poder, sustentan la soberanía en la nación y garantizan la libertad de imprenta. Tres Constituciones que han guiado el desarrollo del constitucionalismo universal.

Por su parte, la historia constitucional ecuatoriana ha sido pródiga en la expedición de textos constitucionales y en la incorporación nominal de modernas instituciones democráticas, pero no en el pleno ejercicio del poder con lealtad constitucional de sus gobernantes. Podría señalarse que el desfase de la falta de vigencia de los textos constitucionales en la vida social se debe a que la expedición de las cartas políticas se fueron dando al unísono de los cambios políticos y sociales de cada época: unos más estructurales, como la independencia de España y el establecimiento de la República y, otros más coyunturales, como las guerras civiles, las guerras internacionales y las revoluciones civiles y militares, matizados por la presencia de caudillos populistas y militares deseosos de poder.

La expresión evidente de este decurso histórico ha sido la crisis de gobernabilidad del Estado constitucional y la renuncia de las funciones democráticas del Estado de derecho, la autocracia en el poder ha permitido en la historia del Ecuador que las instituciones democráticas terminen subyugadas al caudillismo presidencial.

Esto se ha puesto dramáticamente de manifiesto a lo largo de nuestra historia constitucional, en el divorcio entre la norma constitucional en que se asienta el Estado de derecho y la realidad constitucional que 
demuestra su debilitamiento social, trayendo como consecuencia la realización parcial de los fines de todo Estado Constitucional: esto es, garantizar los derechos fundamentales, asegurar el control y balance del poder y promover el desarrollo. El derecho constitucional en el Ecuador, no ha sido lamentablemente un "derecho para la vida".

De aquí que la crisis del constitucionalismo ecuatoriano requirió repensar los problemas y sus soluciones, en los fundamentos de nuestra historia política para proyectarlo al futuro y así se lo hizo en Montecristi, donde se construyeron sueños con el mejor y más amplio catálogo de derechos, respaldados en garantías y sustentados en nobles y trascendentes valores y principios constitucionales, que encuentran un freno y se neutralizan con una inadecuada estructura del poder en su parte orgánica que llega a proponer el control del poder desde el poder, con un Consejo de Participación Ciudadana que pretende asumir la representación de un pueblo rebelde que siempre se ha movilizado en defensa de la libertad, de la moral pública y de la convivencia democrática combatiendo siempre a tiranos y tiranías.

Para lo cual se debió concebir a la historia constitucional como una disciplina de interpretaciones jurídico-política y no de recuento de hechos, así como, también, del estudio preferentemente de las causas, luchas e ideales del devenir de nuestro pueblo y, de vinculación con las necesidades y urgencias del presente.

En efecto, con la Constitución de Cádiz de 1812 se dio inicio en el Ecuador, en ese entonces Real Audiencia de Quito, al establecimiento de las ideas liberales que se expresaron luego en la primera Constitución del Ecuador independiente.

La Constitución de 1812 condensó el tránsito, de las colonias americanas y por ende del Ecuador, de un despotismo absoluto del derecho divino de los reyes a la soberanía popular, de la censura del Tribunal de la Inquisición a la libertad de imprenta y, de la concesión de los altos cargos públicos para los españoles peninsulares a la elección de autoridades locales, la libertad de comercio e industria, la efímera abolición del tributo indígena, entre otros.

Este proceso de liberalización del poder que venía gestándose desde mediados del siglo XVIII; entró a regir institucionalmente a partir de la Constitución de Cádiz en la vida política y económica de las élites regionales, llegando a afectar sus intereses locales. No obstante, en una fase posterior de maduración de la crisis colonial los valores liberales de esta Carta Magna -conocida como "La Pepa"- Ilegarían a formar parte de la conciencia independentista ecuatoriana, aunque lamentablemente sin contar con un proyecto republicano que consolidará al país como una Nación integrada por todas las naciones y pueblos que la integraban.

Durante la República, ello no fue una constante que caracterizó a la historia política del Ecuador, más preocupado por la aprobación de textos constitucionales antes que por asentar un orden social y estatal democrático, de conformidad con los valores, principios y derechos constitucionales en ellos establecidos.

Los operadores políticos no han sido capaces de procesar los fenómenos políticos, económicos, sociales y culturales en el marco de los principios democráticos y las 
reglas constitucionales y por ello, con honrosas excepciones, han quedado en deuda con la historia.

La carencia de diálogo social, de un consenso mínimo o pacto social, ni siquiera entre las élites dirigentes, para asegurar un Estado de derecho duradero, trajo como consecuencia la inestabilidad jurídicopolítica. Esa falta de acuerdo nacional creó también una cultura cívica de incredulidad en la sociedad respecto del Estado y de la Constitución, de la política y los políticos; debido a que las necesidades e ilusiones de la mayoría de la población no fueron satisfechas por las grandes corrientes ideológicas y políticas, en cualquiera de sus constituciones:

Dichas constituciones libertarias y republicanas, además, siempre han buscado cerrar una etapa política e inaugurar una nueva, usualmente autodenominada revolucionaria o de refundación.

Ello no debe ser óbice para entender que el necesario fortalecimiento del Estado constitucional del Ecuador debe ser una obra de todos, pero con lealtad al mejor pasado democrático constitucional y abierto a las demandas de la hora presente y futura.

Precisamente, porque hoy, "el derecho constitucional aparece como una de las escasas posibilidades sólidas para articular legítimamente una defensa de los intereses generales y ofrecer una regeneración éticopolítica; el fortalecimiento del Estado constitucional se ha convertido en la más alta expresión, no sólo del Estado de Derecho y de Derechos y Justicia, sino sobre todo del control y balance del poder, así como de la defensa de los valores de la libertad y la igualdad, como quedó consagrado en la Constitución de Cádiz de 1812.
Con el gran salto cualitativo en el perfil de ese Estado hacia el campo social en búsqueda del desarrollo humano con equilibrio hombre-naturaleza; con búsqueda permanente del "Buen Vivir" conforme a la cosmovisión Andina a la que nos debemos.

Según Luis Navarro García, en su ensayo sobre "El orden tradicional y la revolución de la independencia en Iberoamérica"

La Independencia de Iberoamérica es, probablemente el mayor desastre sufrido por un Imperio colonial y su Metrópoli en su proceso de descolonización. Ha sido uno de los mayores traumas (si no el mayor) padecido por las naciones americanas y España, tanto por la duración y violencia del suceso, como por las secuelas que dejó en ambas partes.

El Estado español en Indias tuvo una organización visible, un aparato que nos es bien conocido, desde los Virreyes hasta los Corregidores, aparato que cumplía las esperadas funciones de dirección o gobierno, de administración de justicia y de exacción fiscal, que aparte de originar remesas de caudales para la tesorería real en la península, permitía costear los gastos de la misma administración indiana.

El Estado Indiano, era una organización sujeta a procesos de ampliación y perfeccionamiento durante siglos, y regularmente contó con servidores eficaces y recursos económicos suficientes para llevar adelante, al menos sus cometidos esenciales. En la Segunda mitad del Siglo XVIII, las grandes reformas Borbónicas fueron el último reajuste hecho para colocar a esa organización en condición de producir aún mejores rendimientos y convertirla en instrumento lo más dócil posible de la voluntad del Monarca. 
Estado indiano-controlado desde la Metrópoli- establecía y expresaba un cierto grado de centralización e interdependencia entre distintos territorios del Imperio, que fue intensamente reivindicada en la vida republicana.

Por lo expuesto, la transición de la colonia a la vida independiente, determinó convivir y mantener las instituciones políticas $y$ administrativas vigentes en la colonia, lo cual se reflejó en las Constituciones ecuatorianas no sólo del S. XIX, sino aún en instituciones del Constitucionalismo del $\mathrm{S}$. XXI.

Pero la mención a las instituciones políticas que se proyectaron a la vida republicana luego de la colonia, necesariamente nos obliga a señalar también que la presencia de los poderes reales en la vida democrática del País tienen sus orígenes allí, donde se entronizó, el poder económico, de la Iglesia y de los militares en el majo del poder político.

Avanzando en el tiempo diremos que el nuevo constitucionalismo latinoamericano es una ideología y una teoría del derecho que ha tenido una enorme influencia en los últimos años en la región. En el caso particular del Ecuador esta es la doctrina que ilustra el proceso constituyente y el cambio institucional que está viviendo el país.

Los nuevos modelos constitucionales desarrollados en América Latina, especialmente en Bolivia (2009), Ecuador (2008), Venezuela (1999), Argentina (1994) y Colombia (1991), tratan de materializar las demandas reclamadas por sus pueblos, teniendo como su objetivo principal la eliminación de las inequidades sociales, políticas y económicas que se vivían en la región, es decir, el Nuevo
Constitucionalismo Latinoamericano, nace en momentos de crisis, frente a la desinstitucionalización, la desconfianza, la incertidumbre, la corrupción, la crisis de gobernabilidad, la ineficiencia de la economía, la privatización de los sectores estratégicos como el energético, la marginación social de los grupos indígenas.

Desde mi perspectiva, América Latina se encuentra atravesando por un momento histórico de gran novedad y cargado de esperanzas en lo político, social y económico, sin embargo, es un modelo del cual todavía se esperan resultados, que esperamos sean siempre positivos, para bien de nuestros pueblos.

Por lo demás, la Constitución de Cádiz no solo fue luz intelectual para el liberalismo y el constitucionalismo de las nacientes repúblicas latinoamericanas, sino que su espíritu libertario, contrario a la invasión napoleónica, fue ejemplo también de rebeldía, de afirmación de la soberanía, como condición para el ejercicio de la libertad. Todo ello nos enseñó Cádiz, todo ello sirve aún hoy y tiene mucha actualidad; por eso, un homenaje al bicentenario de esta Constitución es más que merecido y seguramente aleccionador. 